\title{
Comparisons of commercial Triladyl and locally manufactured extenders for the chilling of semen and their effects on pregnancy rates after transcervical $A I$ in Bangladeshi Indigenous (Ovis aries) sheep
}

\author{
Azizunnesa Rekha ${ }^{1,4}$, B.F. Zohara ${ }^{2}$, F.Y. Bari ${ }^{3}$, M.G.S. Alam ${ }^{3}$ \\ ${ }^{1}$ Department of Medicine and Surgery, Faculty of Veterinary Medicine, Chittagong Veterinary and Animal Sciences University, \\ Khulshi, Chittagong-4202, Bangladesh. \\ ${ }^{2}$ Department of Medicine, Surgery and Obstetrics Faculty of Veterinary \& Animal Science Hajee Mohammad Danesh Science \& \\ Technology University, Basherhat, Dinajpur-5200, Bangladesh. \\ ${ }^{3}$ Department of Surgery and Obstetrics, Faculty of Veterinary Science, Bangladesh Agricultural University, Mymensingh-2202, \\ Bangladesh.
}

\begin{abstract}
Two different extenders were compared for their effects on preservation of semen from Indigenous rams and on pregnancy rate (PR) in Indigenous ewes. Semen was collected from nine Indigenous rams (Ovis aries) once a week using an artificial vagina. Each ejaculate was divided into 2 aliquots, diluted with either commercial $\left(\right.$ Triladyl $^{\circledR}$ ) or locally manufactured (tris, fructose, citric acid, egg yolk: TFE, prepared in own laboratory) extenders and kept at $4^{\circ} \mathrm{C}$ for $48 \mathrm{~h}$. Motility, viability, functional integrity and morphological changes were evaluated at 0,24 and $48 \mathrm{~h}$. Synchronized oestrus ewes inseminated transcervically with 24 and 48 $\mathrm{h}$ of preserved chilled semen diluted with Triladyl and TFE extenders separately. Semen preserved in Triladyl had better motility, viability, and functional integrity at 24 and $48 \mathrm{~h}(\mathrm{P}<0.001)$ than did in TFE. The morphologically normal spermatozoa up to $48 \mathrm{~h}$ of preservation did not differ between extenders. However, in abnormalities studied, Triladyl had detrimental effect on sperm acrosome and TFE on sperm tail $(\mathrm{P}<0.001)$ at 24 and $48 \mathrm{~h}$ of preservation. But, midpiece was not affected by any extender $(P>0.05)$ over the entire period of preservation. The quality of semen decreased $(\mathrm{P}<0.001)$ with increasing preservation time for both extenders. The extenders did not differ $(\mathrm{P}>0.05)$ the overall PR after transcervical AI (TCAI) in ewes. Increased preservation time $(48 \mathrm{~h})$ negatively affected the PR in TFE extended semen compared with than that of Triladyl. The results suggest that the quality of chilled semen (motility, viability, and functional integrity) is more improved when preserved in Triladyl than if extended with a TFE. PR may higher when TCAI is performed with chilled semen preserved in Triladyl for a longer time than TFE. However, TFE extender may be used to dilute the semen for chilling and used in TCAI to get similar PR of Triladyl up to 24 $\mathrm{h}$ of preservation.
\end{abstract}

Keywords: chilled semen, indigenous sheep, locally manufactured extender, TCAI, triladyl.

\section{Introduction}

While the interest in semen preservation has been amplifying worldwide with time, and researchers are trying to compensate the loss of semen quality during storage, the indigenous so-called Wera (local) sheep breed in Bangladesh is far from such study. Preservation of semen and maintenance of possible high quality are prime requirements for AI to obtain the full benefits. In ewes, still, cooling or chilling semen is preferred in transcervical AI (TCAI) as it gives higher percentages of motile spermatozoa compared with cryopreserved semen (Vera-Munoz et al., 2011; Budai at al., 2014). The main problem with cryopreserved semen is the great variability and rather low fertility results (depending on the breed, though). Laparoscopic insemination guarantees good fertility results (Killen and Caffery, 1982) but it is more expensive and difficult to carry out in our country where the veterinary field is not well developed yet. Furthermore, chilled semen is simpler to handle. AI is one of the important and reliable ways to test semen to verify if it is fertile or not. Thereby, evaluation of basic qualitative traits of preserved semen is most important to semen selection for AI (Bozkurt et al., 2011). An ideal extender is needed to maintain the survivability of spermatozoa during storage (Salamon and Maxwell, 2000). The basic components of semen extenders are energy (sugars such as glucose and lactose) and a buffer medium (different inorganic or organic salts; Salisbury et al., 1978). The most common semen extenders for sheep are based on Tris and egg yolk. There were studies conducted to compare ram semen quality after chilling diluted with commercial extenders (Kasimanickam et al., 2011; Hegedüšova et al., 2012). However, there are no reports regarding chilled preservation of indigenous ram semen with commercial specially Triladyl and tris fructose egg yolk (TFE) extenders and their effects on PR in Indigenous ewes in Bangladesh. This study was designed to determine the efficacy of Triladyl and TFE extenders for the chilling of semen and its effects on PR in Indigenous sheep.

\section{Materials and Methods}

Experimental animals and management

The experiment was conducted between January 2012 and February 2013 at the Department of 
Surgery and Obstetrics, Bangladesh Agricultural University (BAU), Mymensingh-2202 (N 24.73 and E 90.44). The area receives on average $174 \mathrm{~mm}$ of rainfall. Mean annual minimum and maximum temperatures experienced at the site are 16.5 and $29.1^{\circ} \mathrm{C}$, respectively. Nine Indigenous rams from the Departmental project (BAS-USDA; LS-11) stock and 169 ewes were bought from local market to be used in this study. The rams and ewes were in same age of 2 to 3 years old. The body weight of ewes and rams was 14 to $17 \mathrm{~kg}$ and 20 to $26 \mathrm{~kg}$, respectively. The scrotal circumference of rams was 20 to $24 \mathrm{~cm}$. After selection and bought from local market, the ewes were bathed with fresh water. They were ultrasonography scanned to diagnose non pregnant and other physiological and clinical tests were performed to confirm gynecological soundness. They were assigned to the management system so that their body condition score (BCS) improved at least two months before starting TCAI. When they gained BCS $\geq 2.0$ they were allowed to TCAI. The BCS of rams was 2.5-4 (1-5 scoring). During the study they were kept under semi intensive conditions at the Departmental animal shed, BAU. They were given anthelmintic treatment and vaccinated against rabies and tetanus routinely. All these mentioned treatments were completed before two months of starting AI. The animals were maintained on natural grazing supplemented with concentrates (300 $\mathrm{g} /$ head/day) that consisted of wheat bran $(50 \%)$, crushed maize $(25 \%)$, soy bean meal $(20 \%)$, fish meal $(1 \%)$, dicalcium phosphate (DCP) powder $(2 \%)$, vitamin mineral premix $(0.5 \%)$ and salt $(1.5 \%)$ with water always available.

Brief description of reproductive performances of indigenous ewes in Bangladesh

The Bangladesh indigenous ewes are small in body size, 15 19 kg body weight for 2-3 years old age (Roy et al., 2014; Zohara et al., 2014a), age at puberty $8.4 \pm 1.2$ months, weight at puberty $9.2 \pm 1.0 \mathrm{~kg}$, oestrus cycle length in days $16.1 \pm 0.4$, duration of estrus 32.8 $\pm 3.2 \mathrm{~h}$, gestation length $141.8 \pm 1.2$ days, post partum onset of estrus $42.5 \pm 5.6$ days, pregnancy rate 83.3 by natural service, lamb birth weight $1.0 \pm 0.3 \mathrm{~kg}$, weaning weight $3.58 \pm 0.93 \mathrm{~kg}$, pre-weaning average daily weight gain $42.6 \pm 14.4 \mathrm{~g} / \mathrm{day} / \mathrm{lamb}$, lambing rate 75 , litter size $1.2 \pm 0.4$, lamb survival rate $91.67 \%$ (Zohara et al., 2014b).

\section{Preparation of extender}

Two types of semen extenders were used; a TFE extender prepared in the laboratory and Triladyl ${ }^{\circledR}$ (Minitube, Germany). All chemicals for making extenders were purchased from Sigma Aldridge (Spain). The locally-manufactured extender (tris, fructose, eggyolk: TFE) was prepared according to Salamon and Maxwell (2000) mixing Tris $3.4 \mathrm{~g}$, fructose $0.5 \mathrm{~g}$, citric acid $2.0 \mathrm{~g}$, penicillin $100000 \mathrm{IU}$, streptomycin $100 \mathrm{mg}$, and deionized water to make $100 \mathrm{ml}$ solution as stock, which was stored at 4 to $5^{\circ} \mathrm{C}$ for a maximum period of two weeks. On the day of semen collection, $20 \mathrm{ml}$ of final working TFE extender was prepared by adding $20 \%$ egg yolk to the stock solution already prepared. Similarly, $20 \mathrm{ml}$ of the final Triladyl extender was prepared by adding 1 volume of Triladyl (contains glycerol, tris, citric acid, fructose, tylosin, gentamicin, lincomycin, and spectinomycin according to the manufacturers' specifications) to 3 volumes of deionized water and 1 volume of egg yolk. After mixing the ingredients both the extenders were filtered by filter paper (Whatman ${ }^{\mathrm{TM}}, 125 \mathrm{~mm} \varnothing \times 100$ circles, GE Healthcare UK Limited, Amersham Place, China).

\section{Experimental design}

Semen was collected using an artificial vagina (AV) from each ram once per week. Before collection of semen, rams were trained for AV. A total of 179 ejaculates were collected from nine Indigenous rams. Each ejaculate was examined for volume, color, density, sperm concentration and mass activity. Semen volume was estimated in a graduating tube just after collection. Color and density of semen were estimated visually and tube slant, respectively. Sperm concentration was determined using a Neubauer counting chamber. Mass motility was estimated by assessment of wave motion of fresh undiluted semen under microscope $10 \times$ on a scale of 0 to 5. Thereafter, each semen sample was divided into two equal aliquots for dilution into TFE and Triladyl extender. Semen samples were diluted to a final concentration of $400 \times 10^{6}$ spermatozoa $/ \mathrm{ml}$. Samples were thereafter preserved at $4^{\circ} \mathrm{C}$ for up to $48 \mathrm{~h}$ for evaluation.

\section{Semen evaluation}

Motility, viability, functional integrity and morphology of spermatozoa were evaluated to observe the effects of two different extenders on 0,24 and $48 \mathrm{~h}$ of chilling time. A phase-contrast microscope (Gallenhamp, No. 82TT8, Cat No.M/6-200-H HZ 60, England) was used for microscopic evaluation. Sperm motility was evaluated subjectively using $400 \mathrm{X}$. Diluted $(5 \mu \mathrm{l})$ semen was placed directly on a microscope slide and covered by a cover slip. For each sample, different microscopic fields were examined. The mean of the three successive evaluations was recorded as the final percentage motility. Sperm viability was assessed by staining with eosin-nigrosin and hypo osmotic swelling (HOS) test was used to detect the functional integrity of spermatozoa (Jeyendran et al., 1984). Sperm morphology was assessed by microscopic examination after Spermac ${ }^{\circledR}$ (Minitube, Box 152, Wellington, 7654, South Africa) staining (Schafer and Holzman, 2000).

\section{Oestrus synchronization and heat detection}

Ewes were treated with Ovuprost $^{\mathrm{TM}}$ (Cloprostenol sterile injection, BOMAC, Laboratories Ltd, New Zealand)@0.4 ml im/ewe double times at 9 day intervals (Zohara et al., 2014a). Oestrus was checked twice daily using vasectomized ram (teaser) 
Rekha et al. Extenders for the chilling of ram semen and pregnancy rates.

spending at least $30 \mathrm{~min}$ for each check time.

\section{Preparation of semen for transcervical AI}

Triladyl and TFE diluted chilled semen preserved for 24 and $48 \mathrm{~h}$ were warmed up at room temperature for 5-6 min and loaded into $0.25 \mathrm{ml}$ straws (Minitub GmBH, Tiefenbach, Germany). Before loading the semen, it was examined microscopically to have a minimum $60 \%$ sperm motility. The semen straws were then loaded into sheep AI pipette just before insemination.

\section{Transcervical AI in Indigenous ewes}

Synchronized oestrous ewes were restrained in a laparoscopic cradle in ventral to the cradle surface at a $45^{\circ}$ angle position. The perineal region was cleaned and the external genitalia lubricated applying non spermicidal jelly (Priority Care ${ }^{\circledR}$, First Priority, Inc, Elgin, IL U.S.A). After positioning the ewe, a sterile lubricated BCROSIL ${ }^{\circledR}$ test tube was inserted into the vagina of the ewes. The os of the cervix was visualized by using laparoscopic light source or penlight. Sheep insemination pipette with an excentrical tip (Minitube, Germany) with $0.25 \mathrm{ml}$ semen straw was introduced in to the cervix and tried to push forward by manipulating through the cervical rings. Semen was then expelled from the pipette as deeply as possible in the cervix (Kumar and Naqvi, 2014; Rekha et al., 2016).

\section{Pregnancy diagnosis}

Pregnancy was diagnosed by observing non return rate over two cycle of post insemination and all inseminated ewes were subjected to abdominal ultrasonography scanning for the presence of fetus using a Digital Ultrasonic Diagnostic Imaging System with Linear Rectal Ultrasonic Transducer 5.0 MHz (Model Magic 5000, Art No. 303700, Germany) after 40 days post insemination.

\section{Statistical analysis}

The data were subjected to analysis of variance with respect to extenders, preservation time, oestrus type, and PR using SPSS 17.0 computer program package (SPSS, Chicago, IL, USA). Two way ANOVA was done to evaluate the effects of two different extenders and three different preservation times on quality of spermatozoa. Chi-square with Fisher's exact test was done to compare the PR between preservation times, within types of semen. The similar test was performed to compare the overall PR in ewes inseminated with Triladyl and TFE extenders. Significance was accepted at $\mathrm{P}<0.05$.

\section{Results}

The mean semen volume was $1.3 \pm 0.2 \mathrm{ml}$, creamy to creamy white in color with a density of $3.0 \pm$ 0.4 (1-5 scale, arbitrary units), mass motility of $4.4 \pm$ $0.6(0-5$ scale $)$, and concentration of $4.7 \pm 1.5 \times 10^{9} / \mathrm{ml}$.

Significantly higher percentages $(\mathrm{P}<0.001)$ of progressively motile sperm cells were recorded in Triladyl diluted chilled semen $(82.9 \pm 0.3,75.5 \pm 0.3)$ at 24 and $48 \mathrm{~h}$ of observations than that in TFE extender $(80.4 \pm 0.3,72.7 \pm 0.3 \%$ ), respectively (Fig. 1 ). Similarly, the percentage of viable and functional integrity of sperm cells was higher $(\mathrm{P}<0.001)$ in Triladyl than TFE extended chilled semen on both 24 and $48 \mathrm{~h}$ of observation (Fig. 2 and 3 ).

The rate of morphologically normal spermatozoa at 0,24 and $48 \mathrm{~h}$ of preservation did not differ between Triladyl $(93.3 \pm 0.1 \%, 85.1 \pm 0.2 \%, 77.0$ $\pm 0.2 \%)$ and TFE $(93.1 \pm 0.1 \%, 84.8 \pm 0.1 \%, 76.6 \pm$ $0.2 \%$ ) extended semen (Fig. 4). However, all the parameters studied in this research decreased significantly $(\mathrm{P}<0.001)$ with increasing preservation time for both extenders (Fig. 1-4).

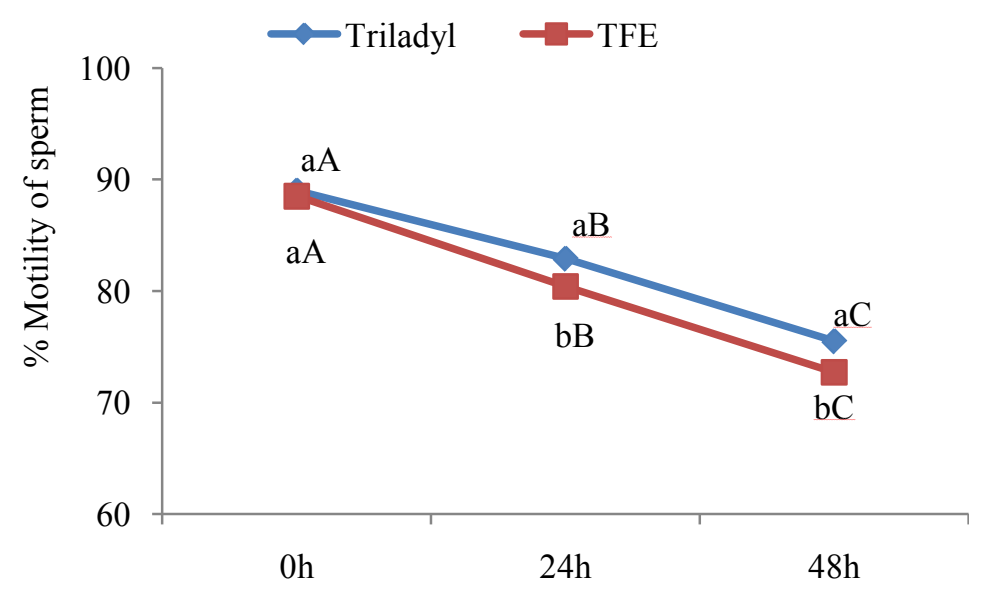

Figure 1. Effect of extenders and preservation times on sperm motility. Different superscript letters $(a, b)$ indicate significant difference $(P<0.05)$ between extenders and $(\mathrm{A}, \mathrm{B}, \mathrm{C})$ among preservation times. 


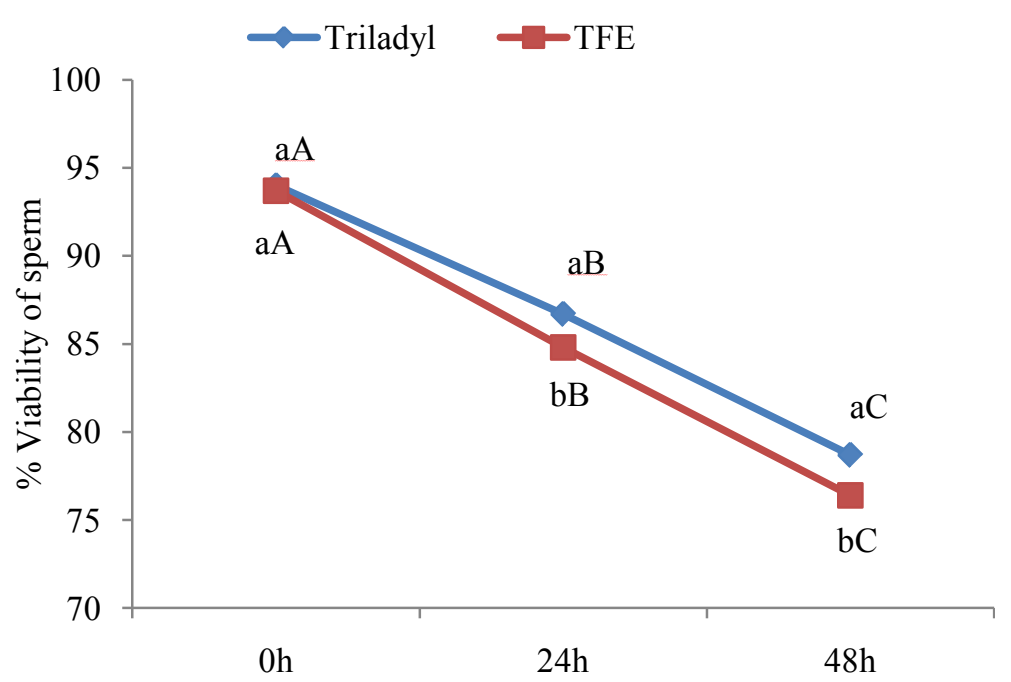

Figure 2. Effect of extenders and preservation times on sperm viability. Different superscript letters $(a, b)$ indicate significant difference $(P<0.05)$ between extenders and $(\mathrm{A}, \mathrm{B}, \mathrm{C})$ among preservation times.

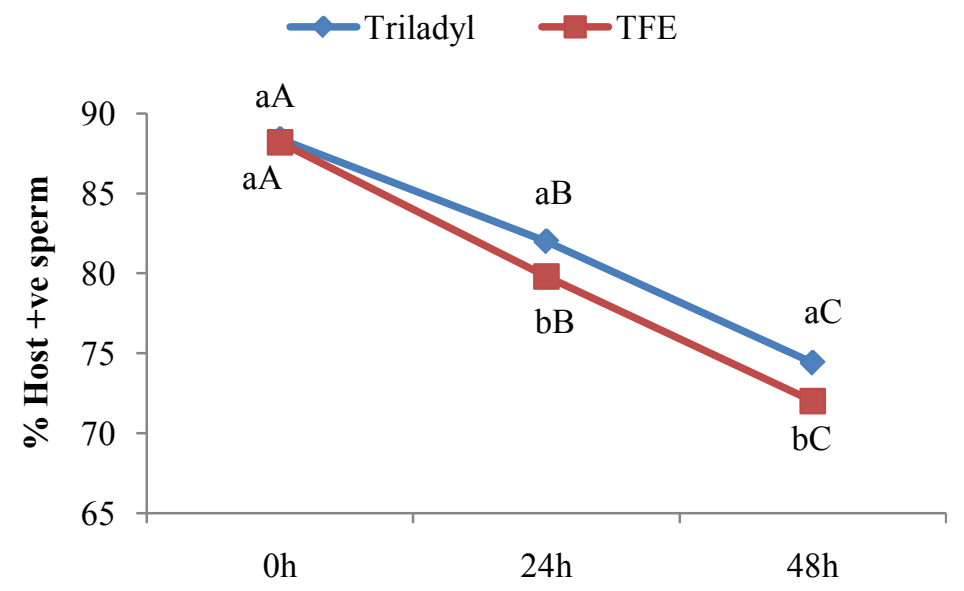

Figure 3. Effect of extenders and preservation times on sperm functional integrity. Different superscript letters $(a, b)$ indicate significant difference $(\mathrm{P}<0.05)$ between extenders and $(\mathrm{A}, \mathrm{B}, \mathrm{C})$ among preservation times.

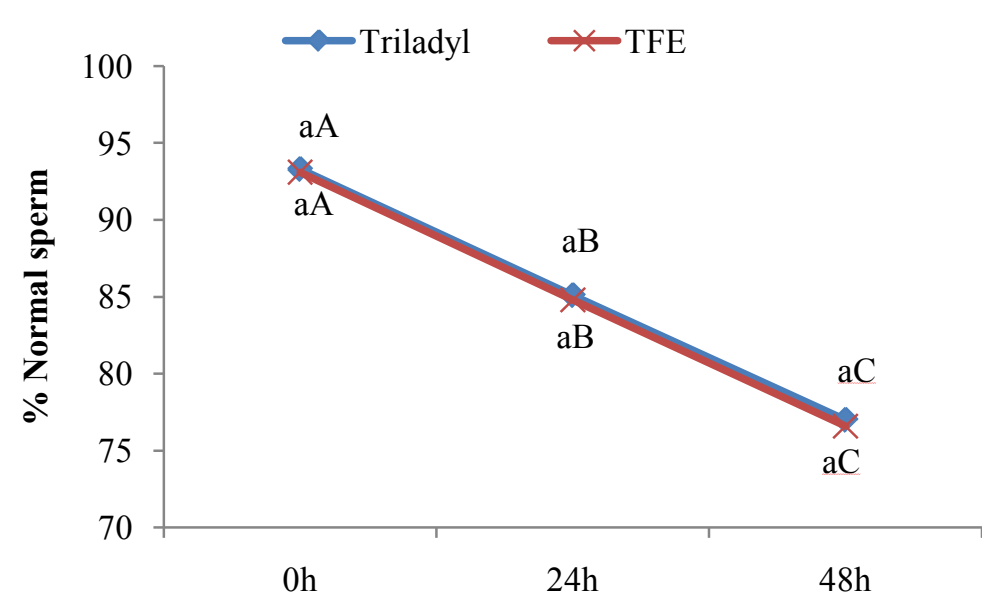

Figure 4 Effects of extenders and preservation times on normal sperm morphology. Superscript letters $(\mathrm{a}, \mathrm{a})$ and $(\mathrm{A}, \mathrm{B}, \mathrm{C})$ indicate non-significant and significant difference $(\mathrm{P}<0.05)$ between extenders and among preservation times, respectively. 
Among the parameters regarding semen abnormalities studied (acrosome, midpiece and tail), Triladyl had detrimental effect $(\mathrm{P}<0.05)$ on acrosome and TFE on tail of spermatozoa at 24 and $48 \mathrm{~h}$ of preservation. However, neither TFE nor Triladyl had any effect $(\mathrm{P}>0.05)$ on sperm midpiece in any observation (Fig. 5, 6 and 7).
There was no difference $(\mathrm{P}>0.05)$ in overall PR between Triladyl and TFE diluted chilled semen after TCAI. However, Triladyl diluted semen preserved for $48 \mathrm{~h}$ increased PR $(\mathrm{P}<0.05)$ compared to TFE diluted chilled semen preserved for the same time as Triladyl in ewes (Table 1).

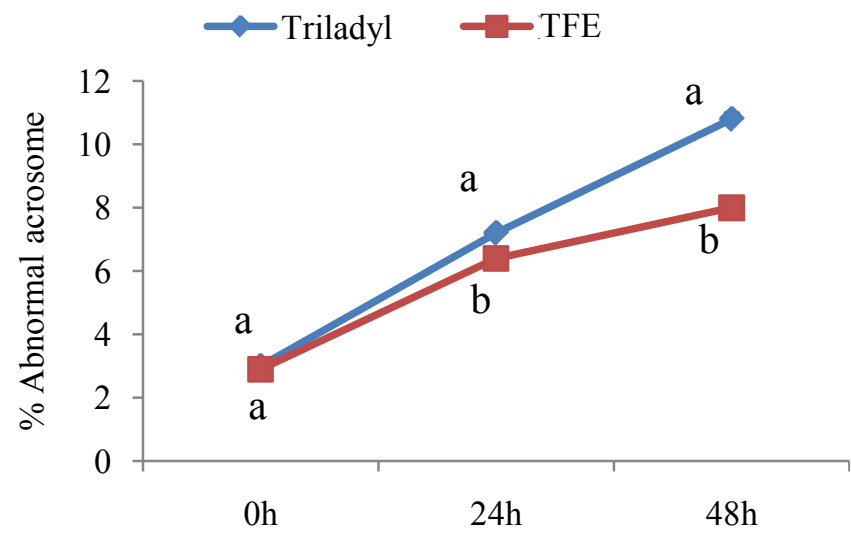

Figure 5. Effects of extenders and preservation times on sperm acrosome. Different superscript letters $(a, b)$ indicate significant difference $(P<0.05)$ between extenders and $(\mathrm{A}, \mathrm{B}, \mathrm{C})$ among preservation times.

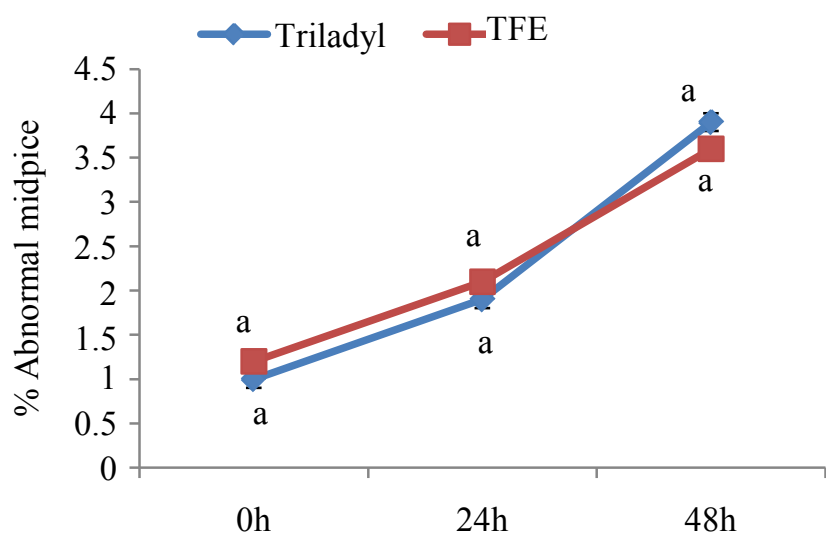

Figure 6. Effects of extenders and preservation times on sperm midpiece. Similar superscript letters $(a, a)$ and different letters $(A, B, C)$ indicate non-significant and significant difference between extenders and among preservation times, respectively at $\mathrm{P}<0.05$.

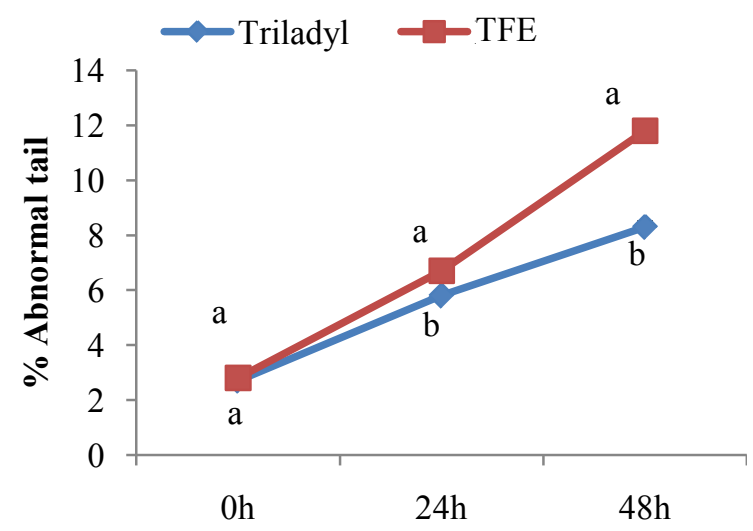

Figure 7. Effects of extenders and preservation times on sperm tail. Different superscript letters $(a, b)$ and $(A, B, C)$ indicate significant differences between extenders and preservation times, respectively at $\mathrm{P}<0.05$. 
Rekha et al. Extenders for the chilling of ram semen and pregnancy rates.

Table 1. Comparison between Triladyl and TFE diluted chilled semen on PR following TCAI

\begin{tabular}{|c|c|c|c|c|c|c|}
\hline \multirow[t]{2}{*}{ Type of treatment } & \multirow[t]{2}{*}{ Chilling time } & \multirow[t]{2}{*}{ Inseminated ewes } & \multirow[t]{2}{*}{ Pregnant ewes } & \multirow[t]{2}{*}{ PR (\%) } & \multicolumn{2}{|c|}{ Overall } \\
\hline & & & & & $\mathrm{I} / \mathrm{P}$ & $\mathrm{PR} \%$ \\
\hline Triladyl & $24 \mathrm{~h}$ & 44 & 12 & $27.3^{\mathrm{a}}$ & $86 / 23$ & $26.7^{\mathrm{a}}$ \\
\hline & $48 \mathrm{~h}$ & 42 & 11 & $25^{\mathrm{a}}$ & & \\
\hline TFE & $24 \mathrm{~h}$ & 41 & 11 & $26.8^{\mathrm{a}}$ & $83 / 14$ & $16.9^{\mathrm{a}}$ \\
\hline & $48 \mathrm{~h}$ & 42 & 3 & $7.1^{\mathrm{b}}$ & & \\
\hline
\end{tabular}

$\mathrm{I}=$ Inseminated ewes, $\mathrm{P}=$ Pregnant ewes, $\mathrm{PR}=$ pregnancy rate. Superscript $\left.{ }^{\mathrm{a}}{ }^{\mathrm{a} b}\right)$ indicate significant difference $(\mathrm{P}<0.05)$ within column in respect of extenders within chilling time.

\section{Discussion}

During chilling, commercial extender; Triladyl was superior to retain better $(\mathrm{P}<0.05)$ semen quality than locally manufactured; TFE extender on 24 and $48 \mathrm{~h}$ observations. With little exception our results were similar to those reported by Kasimanickam et al. (2011). They found that there was significant difference of motile spermatozoa between commercial Triladyl (egg yolk based) and Triladyl (milk based) extenders on day 2 of chilling. However, we did not find the difference of semen quality on $0 \mathrm{~h}$ of observation between two extenders. Similarly, tris citric acid based extender reported to be the best for chilling with retaining better motile sperm compared with sodium citrate and skim milk. They did not get any differences of sperm parameters on day 0 of liquid storage (Rakha et al., 2013). The present finding is also strengthened by the report of Pérez-Garnelo et al. (2006). They showed that there was no difference in sperm motility between Triladyl and tris citrate diluted semen at $0 \mathrm{~h}$ of preservation. Preservation time had a negative effect on motility of spermatozoa for both the extenders used in this study. A similar finding was observed by other scientists (Kasimanickam et al., 2007; Gundogan et al., 2011). Our study revealed that the motility of spermatozoa was reduced with increasing preservation time, however, the mean motile sperm was $75.5 \%$ up to $48 \mathrm{~h}$ of storage, a time which is acceptable for AI according to Olivera-Muzante et al. (2011). Taken together, these results showed that Triladyl gives better support to sperm motility after storage at $4^{\circ} \mathrm{C}$ than TFE.

The present results showed that the differences of sperm viability between semen diluted in Triladyl and TFE reflected the differences that were also present in sperm motility. Sperm viability after storage at $4{ }^{\circ} \mathrm{C}$ varied with extender in ram (Rakha et al., 2013). Previous studies observed that Triladyl showed better sperm viability after $24 \mathrm{~h}(81.2 \%)$ of storage at $4^{\circ} \mathrm{C}$ compared with semen stored in other extenders $(78.6 \%$ for Andromed or $77.9 \%$ for Biladyl; Hegedüšova et al., 2012). In order to get a satisfactory conception rate, cold semen should have $>70 \%$ viable spermatozoa in bovine (Nilani et al., 2012). As expected, the present study showed the mean viability of sperm was reduced from 94 to $79 / 76$ for Trilady/TFE extenders over the time of preservation ( 0 to $48 \mathrm{~h}$ ) which would be within the standard level for AI. The viability of spermatozoa was reduced with increased preservation time. Similar effects of preservation time on chilled semen quality were reported by others (Kasimanickam et al., 2007; Gundogan et al., 2011).
Diagnosis of infertile semen is probably the most essential parameter in relation to semen evaluation for AI of livestock. Regarding functional integrity, hypo osmotic solution (HOS) test showed higher percentages of functional integrated sperm in Triladyl diluted semen than TFE chilled semen. Several studies observed that functional integrated sperm were significantly differed with extenders. Our results were in agreement with the findings of others (Gundogun, 2009; Rakha et al., 2013) who found higher viable sperm in tris citric acid based extender compared with sodium citrate and skimmed milk based extender. The result in this study showed that HOS test values at $0 \mathrm{~h}$ of observation did not differ between extenders. With increasing preservation time, functional integrity of ram sperm decreased, which was not different from others (Kasimanickam et al., 2007; Gundogan et al., 2011). Although, determination of fertilizing capacity of semen should not rely on any single test (Mordel et al., 1993) and, like other functional tests for sperm, the HOS test does not provide unequivocal information regarding the fertilizing ability of the spermatozoa (Kiefer et al., 1996). The HOS test for investigating sperm plasma membrane integrity nevertheless, is considered a useful assay in the diagnosis of infertile semen (Jeyendran et al., 1984).

Sperm morphology is often used as an important criterion in the evaluation of semen in domestic animals (Howard et al., 1983). Semen with high percentages of abnormalities has reduced fertility after insemination (Larsson, 1988). Our results showed that extender had no effect on normal sperm morphology after dilution and cooling at $4{ }^{\circ} \mathrm{C}$. This finding was not dissimilar to the reported by others (Pérez-Garnelo et al. 2006). Contrary, Gundogan et al. (2011) reported that significant effects of extenders on the proportion of normal spermatozoa in rams. Like other semen parameters, the rate of normal sperm morphology decreased with preservation time. The information on comparative effects of extenders on chilled semen morphology is very scanty in Bangladesh. Indifferent effect of extenders on normal morphology of indigenous chilled ram semen might be the positive criterion to select extender for storage of ram semen in Bangladeshi researchers or sheep breeders. Moreover, the quality of preserved semen depends on processing and handling of individuals. Different researchers may observe different values for the same things in different laboratories.

We also calculated the effect of extenders on acrosome, midpiece, and tail, which is essential for fertilization of ova (Swain and Miller, 2000). Although 
there were no effects of extenders on normal sperm morphology, Triladyl had detrimental effects on acrosome compared with TFE at 24 and $48 \mathrm{~h}$ of observations among different abnormalities (acrosome, midpiece, and tail). Increase in sperm cells with abnormal acrosome in Triladyl diluted semen could be due to the effect of toxins that may be produced from glycerol presents in Triladyl. Toxicity of glycerol in bull semen at chilling temperature was observed by VeraMunoz et al. (2011). The sperm tail abnormality rate was increased in semen when preserved with TFE compared with Triladyl.

In this study even though the Triladyl is superior to maintain better sperm quality than TFE during chilling, TFE extender is not inferior to produce overall PR (Table 1). We have done TCAI in induced oestrus ewes using Triladyl and TFE extended chilled ram semen. It seems that the basic composition of Triladyl and TFE extender is similar and could be the reason behind non different overall PR. Although, the difference between overall PR is nonsignificant, it seems that the tendency of Triladyl is to produce higher PR than TFE. This might be due to better quality of semen used in AI which maintained Triladyl. To our knowledge, there is still no report regarding comparative effects of study between Triladyl and TFE extenders on PR in Indigenous sheep. Furthermore, international information about effects of Triladyl and TFE (Tris based) extenders used in chilled ram semen and observed PR after TCAI is very scanty. However, the overall PR in our study is lower than that observed by Paulenz et al. (2003). They obtained 52\% PR rate in Norwegin Crossbred ewes using chilled semen diluted with commercial Tris based extender. Another study conducted by Menchaca et al. (2005) obtained 43\% PR after TCAI using chilled semen diluted with tris citrate which is also higher than our result (Table 1). They found higher PR with semen which was preserved for $12 \mathrm{~h}$ at $5^{\circ} \mathrm{C}$ whereas we used semen which was preserved for 24 and $48 \mathrm{~h}$ at $4^{\circ} \mathrm{C}$. Considering this preservation time and proven by Menchaca et al. (2005) that $24 \mathrm{~h}$ preserved semen at $5^{\circ} \mathrm{C}$ reduced $20 \%$ PR than that of fresh, our result is to be acceptable for both extenders.

Though the difference of semen quality between extenders was very small during chilled preservation, it showed significant agreement with others (Abdelhakem et al., 1991). However, in a field trial by TCAI, this small difference in semen quality proved practically invalid turn out non different overall PR. In another sense, this small difference of higher quality Triladyl diluted semen preserved for $48 \mathrm{~h}$ increased PR compared with TFE. It is hereby proven that good quality semen is required to get higher PR. Interestingly PR was not affected when insemination was done with Triladyl extended semen preserved for $48 \mathrm{~h}$. Though the difference of semen quality between extenders was very small during chilled preservation, it showed significant agreement with others (Abdelhakem et al., 1991). However, in a field trial by TCAI, this small difference in semen quality proved practically invalid turn out non different overall PR. In another sense, this small difference of higher quality Triladyl diluted semen preserved for $48 \mathrm{~h}$ increased PR compared with TFE. It is hereby proven that good quality semen is required to get higher PR. Interestingly PR was not affected when insemination was done with Triladyl extended semen preserved for $48 \mathrm{~h}$. Though it is said that the effect of preservation time on PR was negative and increased preservation time reduced PR (Salamon and Maxwell, 2000), however, it is contradictory to our result particularly in Triladyl extended prolong time $(48 \mathrm{~h})$ chilled semen. Thereby it would be said that Triladyl could protect and maintain a higher number of spermatozoa with good quality for longer time in chilling temperature than TFE extender resulting in higher PR. Reversely, PR was significantly reduced when AI was performed with TFE diluted chilled semen preserved for $48 \mathrm{~h}$ compared to $24 \mathrm{~h}$ preserved semen. Besides ordinary evaluation of semen in laboratory, final assessment of semen is of utmost importance which could be done through fertilization test (Rodríguez-Martínez, 2007). Moreover, field AI is one of the reliable ways to test semen fertility. Although the observation is very small, application of chilled semen in TCAI is able to understand that besides laboratory evaluation of semen, a field trial is most appreciated to decide the final use in commercial purposes.

In conclusion, commercial extender (Triladyl) seems to be useful and better as an alternative to the conventional extender (Tris TFE) for the longer time chilling and application in TCAI in Bangladesh. However, TFE extender may be used to chill the semen up to $24 \mathrm{~h}$ and use in AI to get similar PR as Triladyl in ewes. Further study is required to investigate the PR following TCAI using semen in longer time chilling extended with Triladyl and TFE extenders separately in a large number of ewes.

\section{Acknowledgments}

The authors are grateful to the Bangladesh Academy of Science and United States Department of Agriculture (BAS-USDA; LS-11) for financial support. We are also grateful to Professor Dr. Tim Parkinson, Institute of Veterinary, Animal \& Biomedical Sciences, Massey University, New Zealand for his generosity in reviewing this manuscript. There is no conflict of interest in this research.

\section{References}

Abdelhakem AA, Graham EF, Vazquez IA. 1991. Studies on the presence and absence of glycerol in unfrozen and frozen ram semen: Fertility trials and the effect of dilution methods on freezing ram semen in the absence of glycerol. Cryobiology, 28:36-42.

Bozkurt Y, Oğrcetmen F, Kokcu O, Ercin U. 2011. Relationships between seminal plasma composition and sperm quality parameters of the Salmo trutta macrostigma (Dumeril, 1858) semen with emphasis on sperm motility. Czech J Anim Sci, 56:355-364.

Budai C, Egerszegi I, Olah J, Javor A, Kovacs A. 
2014. The protective effect of antioxidants on liquid and frozen stored ram semen. Review. Scient Pap Anim Sci Biotech, 47:46-52.

Gundogan M, Avdatek F, Yen D. 2011. Effect of extenders on motility, morphology and osmotic resistance parameters of ram sperm during liquid storage. Rev Méd Vét, 162:546-551.

Gundogun M. 2009. Short term preservation of ram semen with different extenders. Kafk Univ Vet Fak Derg, 15:429-435.

Hegedúšova Z, Štolc L, Louda F, Čunat L, Vejnar J. 2012. Effect of different extenders on ram sperm traits during storage. Acta Univ Agric Silvic Mendelianae Brun, 14:111-116.

Howard JG, Wildt DE, Chakraborty PK, Bush M. 1983. Reproductive traits including seasonal observation on sperm quality and serum hormone concentration in Dorcas Gazelle. Theriogenology, 20:221-234

Jeyendran RS, Van-Der-Ven HH, Perez-Pelaez M, Zaneveld LJD. 1984. Nonbeneficial effects of glycerol on the oocyte penetrating capacity of cryopreserved and incubated human spermatozoa. Cryobiology, 22:434437.

Kasimanickam R, Kasimanickam V, Pelzer KD, Dascanio JJ. 2007. Effect of breed and sperm concentration on the changes in structural, functional and motility parameters of ram-lamb spermatozoa during storage at $4^{\circ} \mathrm{C}$. Anim Reprod Sci, 101:60-73.

Kasimanickam R, Kasimanickam V, Tibary A, Pelzer K. 2011. Effect of semen extenders on sperm parameters of ram semen during liquid storage at $4{ }^{\circ} \mathrm{C}$. Small Rumin Res, 99:208-213.

Kiefer D, Check JH, Katsoff D. 1996. The value of motile density, strict morphology, and the hypo-osmotic swelling test in vitro fertilization embryo transfer. Arch And, 37:57-60.

Killen ID, Caffery GJ. 1982. Uterine insemination of ewes with the aid of a laparoscope. Aus Vet J, 59:95.

Kumar D, Naqvi SMK. 2014. Effect of time and depth of insemination on fertilityof Bharat Merino sheep inseminated trans-cervical with frozen-thawed semen, $J$ Anim Sci Technol, 56:1-6.

Larsson B. 1988. Distribution of spermatozoa in the genital tract of heifers inseminated with large numbers of abnormal spermatozoa. J Vet Med, 35:721-728.

Menchaca A, Pinezak A, Queirolo D. 2005. Storage of ram semen at $5^{\circ} \mathrm{C}$ : effects of preservation period and timed artificial insemination on pregnancy rate in ewes. Anim Reprod, 2:195-198.

Mordel N, Shemesh A, Dano I. 1993. Novel parameters of human sperm hypo-osmotic swelling test and their correlation to standard spermatogram, total motile sperm fraction, and sperm penetration assay. Fertil Steril, 59:1276-1279.

Nilani K, Eswaramohan T, Balasubramaniam $K$. 2012. Influence of temperature on motility and viability of bovine spermatozoa during cold storage. Int J Sci Res Pub, 2:1-5.
Olivera-Muzante J, Fierro S, Gil J. 2011. Conception rates in ewes after AI with ram semen preserved in milk-egg yolk extenders supplemented with glycerol. Reprod Domest Anim 46:508-512.

Paulenz H, Söderquist L, Adnøy T, Fossen OH, Berg KA. 2003. Effect of milk- and TRIS-based extenders on the fertility of sheep inseminated vaginally once or twice with liquid semen. Theriogenology, 60:759-66.

Pérez-Garnelo SS, Oter M, Borque C, Talavera C, Delclaux M, Martinez-Nevedo E, Palasz, AT, De la Fuente J. 2006. Post-thaw viability of European bison (Bison bonasus) semen frozen with extenders containing egg yolk or lipids of plant origin and examined with a heterologous in vitro fertilization assay. $J$ Zoo Wild Med, 37:116-125.

Rakha BA, Hussain I, Akhter S, Ullah N, Andrabi SMH, Ansari MS. 2013. Evaluation of Tris-citric acid, skim milk and sodium citrate extenders for liquid storage of Punjab Urial (Ovis vignei punjabiensis) spermatozoa. Reprod Biol, 13:238-242.

Rekha A, Zohara BF, Bari FY, Alam MGS. 2016. Comparison of commercial Triladyl extender with a tris-fructose-egg-yolk extender on the quality of frozen semen and pregnancy rate after transcervical AI in Bangladeshi indigenous sheep (Ovis aries). Small Rumin Res, 134:39-43.

Rodríguez-Martinez H. 2007. State of the art in farm animal sperm evaluation. Reprod Fertil Dev, 19:91-101.

Roy PK, Zohara BF, Azizunnesa, Ashit Kumar Paul AK, Bhuiyan MMU, Bari FY. 2014. Oestrus synchronization with Ovuprost ${ }^{\circledR}$ and Prostenol ${ }^{\circledR}$ in the Indigenous ewes of Bangladesh. $J$ Embryo Trans, 29:149-155.

Salamon S, Maxwell WM. 2000. Storage of ram semen. Anim Reprod Sci, 62:77-111.

Salisbury GW, van Demark NL, Codge JB. 1978. Physiology of Reproduction and Artificial Insemination of Cattle. 2nd ed. San Francisco, W.H. Freeman. 798 pp.

Schafer S, Holzman. 2000. The use of transmigration and Spermac stain to evaluate epididymal cat spermatozoa. Anim Reprod Sci, 59:201-211.

Swain JE, Miller RR. 2000. A postcryogenic comparison of membrane fatty acids of elephant spermatozoa. Zool Biol, 19:461-473.

Vera-Munoz O, Amirat-Briand L, Bencharif D, Anton M, Desherces S, Shmitt E, Thorin C, Tainturier D. 2011. Effect of low-density lipoproteins, spermatozoa concentration and glycerol on functional and motility parameters of bull spermatozoa during storage at $4^{\circ} \mathrm{C}$. Asian J Androl, 13:281-286.

Zohara BF, Azizunnesa, Islam MF, Alam MGS, Bari FY. 2014a. Effects of cloprostenol and flurogestone acetate sponge on embryo yields and quality in indigenous ewes in Bangladesh. Anim Prod Sci, 54:1605-1608.

Zohara BF, Azizunnesa, Islam MF, Alam MGS, Bari FY. 2014b. Reproductive Performances of Indigenous Ewes in Bangladesh. IOSR J Agri Vet Sci, 7:64-72. 